Original Article

\title{
PATTERN OF MINI OUTBREAKS OF MUMPS AT SOUTH KASHMIR, PULWAMA, INDIA 2007-2011
}

\author{
Andrabi Syed Arshad H. ${ }^{1}$, Hamid Shamila ${ }^{2}$, Imran Khan ${ }^{3}$ \& Zahoor Ahamad Hamdani ${ }^{4}$ \\ ${ }^{1}$ Consultant / B Grade, Tropical Medical Unit, Multispeciality Hospital, D.H. Pulwama, J \& K, India, \\ ${ }^{2}$ Sr. Resident, Department of Community Medicine, SKIMS, ${ }^{3}$ Assistant Professor of Statistics, SKUAST, \\ ${ }^{4}$ B-Grade Surgeon, Health Department, J \& K, India \\ Correspondence: \\ Andrabi Syed Arshad $\mathrm{H}$. \\ Consultant / B Grade, Tropical Medical Unit, Multispeciality Hospital, D.H. Pulwama, J \& K - 190 023, India \\ Phone : +91 96974 50431, E-mail : syed.arshadhussain@yahoo.co.in
}

\begin{abstract}
:
Background prior to design : Limited outbreaks of mumps do occur in schools and crèches and other public places throughout the globe especially in developing countries like India, despite the introduction of MMR vaccine in 1967-1968. Same is the case with South Kashmir where almost every year mini-epidemics of Mumps do occur which however remain unnoticed, unreported and unnotified.

Design : It was a Hospital based Observational study, carried out from the year 2007 to 2011.

Objective : To find the epidemiologic pattern and clinical presentation of mumps in patients attending a tropical medical unit of Multispecialty hospital(DHP) at South Kashmir, Pulwama, India.

Material \& Methods : All Children fulfilling the criteria for diagnosis of Mumps were recruited in this study from 2007-2011.Their characteristics, the pattern of clinical features were noted besides information regarding history, place, season, month and year of occurrence of disease was collected from the parents of affected children. All these parameters were noted down by a senior internist and infectionlogist of the department, using well-structured proforma. The data so collected was subjected to biostatistical analysis using Fisher exact test and SPSS version 12.

Results : A total of 55 patients were included in the study. All the children had h/o contact with, raw/ semiripened walnuts. Males were 36 and female were 19 in number. None had received any form of mumps/MMR vaccination. All the patients presented in hot summer and in the month of august showing a seasonal trend annually. Bilateral parotitis, a hallmark of mumps was present in all patients. Rural patients usually presented with mild fever .Earache was mainly present in younger age - groups These findings were statistically significant $(P<0.05)$. Out of 55 children, orchitis was seen only in one child. CONCLUSION: Mini-epidemics of mumps occur more frequently in south Kashmir and effect our school children and hamper work output .I can be best prevented by inclusion of mumps/MMR vaccine in national immunization schedule.
\end{abstract}

Keywords: Mumps, school-going children , raw walnut contact, unimmunised, mini-epidemics, late summer, clinical presentation .

\section{Introduction :}

Despite introduction of Mumps vaccine in 1967, mumps continues to be endemic in many countries of the world. This is due to the fact that mumps vaccine is used in only

\begin{tabular}{|c|}
\hline Access this article online \\
\hline Quick Response Code \\
\hline
\end{tabular}
$61 \%$ of the World Health Organization member countries. The industrialized countries, such as the United Kingdom and Japan witnessed several outbreaks since 2004 as they do not routinely vaccinate against mumps ${ }^{11}$, whereas on the other hand it was Finland which was declared be free of the indigenous mumps with the use of national 2 dose trivalent MMR vaccination program. ${ }^{2,3}$ Although in United States mumps disease rates declined $>99 \%$ after vaccine was licensed in 1967, large outbreaks did occur in highly vaccinated populations in 2006 and 2009-2010 and at least 45 US states were involved. An outbreak of mumps occurred unexpectedly in May 2005 and in September 2005 in Canada. In addition the outbreaks have been reported in Czech republic Moldova and Austria in last decade. The epidemiology of mumps in India and the 
magnitude of the problem are not fully appreciated. ${ }^{2,3}$ There is paucity of epidemiologic data regarding mumps which is fairly common in India. Though MMR vaccine has been a part of immunization schedule in the developed countries it is yet to be included in our national immunization programme. Outbreaks occur at interval of 5-10 yrs. in public places, schools or military barracks. The incubation period generally ranges from 1-3weeks. One attack confers lifelong immunity. Mumps virus is transmited by droplet nuclei, salvia, and fomites. Mumps is an enveloped single-stranded RNA pleomorphic ,paramyxo virus belonging to the family paramyxoviridae, which causes an acute highly infectious disease mainly in children and young adults and spreads rapidly in susceptible people living in close proximity. ${ }^{4,5,6}$. There is prodrome of fever, malaise, myalgia and anorexia. The distinctive feature is swelling of one or both parotid glands accompanied by tenderness and obliteration of the space between ear lobe and the angle of the mandible. ${ }^{3}$ The diagnosis is made easily in patients with acute bilateral parotid enlargement in a mini-outbreaks at school or military services or other public places lasting at least 2 days without other apparent cause. The parotid enlargement is bilateral and synchronus or non

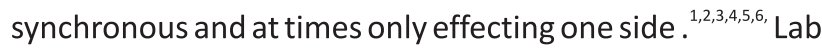
diagnosis is required when only unilateral involvement is there and or when parotitis is absent. The virus is isolated from saliva, throat and urine. PCR can detect it. Presternal oedema has been described in $5 \%$ of mumps cases often in association with submandibular adenitis. Orchitis occurs in post pubertal males almost in $20 \%$ of cases. Oophoritis is less common. Aseptic meningitis, encephalitis, cerebellar ataxia, facial palsy, transverse myelitis, Guillan berre syndrome, aqueductal stenosis leading to hydreocephalus can occur. However it is rarely fatal. ${ }^{2,3,4}$ Pancreatitis can occur , myocarditis, mastitis, thyroiditis, nephritis, arthritis, ,ITP. Spontaneous abortions in gestational mumps can occur in pregnancy. The other diseases which mimic are Sjogrens, diabetes, sarcoidosia, uremia, drugs like phenylbutazone ,thiouracil. Unilateral causes of parotid enlargement apart from mumps are ductal obstruction due to stone/stricture. ${ }^{3}$

OBJECTIVE : 1 . To find the epidemiologic pattern and clinical presentation of mumps patients presenting at a tropical medical unit at a multispecialityhospital at Pulwama, South Kashmir, India. 2. To frame recommendations to prevent these out-breaks to occur.

\section{Material\& Methods:}

It was a hospital based observational study from 20072011. Children fulfilling the criteria for diagnosis of Mumps were recruited in this study from 2007-2011. For the purpose of the outbreaks the following Case definition criteria stated by the Centers for Disease Control and Prevention was used. "A clinical case was defined as a patient with acute onset of unilateral or bilateral tender, self-limited swelling of the parotid and other salivary gland, lasting at least two days and without other apparent cause". However we strictly entertained only those, patients having bilateral parotitis. The history, epidemiological characteristics and the pattern of clinical behaviour were noted. All these parameters were recorded by a senior internist and an infectionlogist of the tropical medical unit. The data was subjected to biostatistical analysis by Fisher exact test using SPSS version 12.

Table 1: Denotes Seasonal \& cyclic trend of outbreaks besides history, N=55

\begin{tabular}{|l|l|c|c|c|}
\hline Year wise & $\begin{array}{l}\text { Season/month } \\
\text { of presentation }\end{array}$ & $\begin{array}{c}\text { h/o } \\
\text { Vaccination }\end{array}$ & $\begin{array}{c}\text { h/o } \\
\text { walnut } \\
\text { contact }\end{array}$ & $\begin{array}{c}\text { No. of } \\
\text { pts. } \mathrm{n}=(\%)\end{array}$ \\
\hline 2007 & Summer/late August & Nil & ++++ & $17(30.90)$ \\
\hline 2008 & Summer/August & Nil & ++++ & $18(32.72)$ \\
\hline 2009 & Summer/ late August & Nil & ++++ & $12(21.84)$ \\
\hline 2010 & Summer /any other season & - & - & - \\
\hline 2011 & Summer/August & Nil & ++++ & $8(14.54)$ \\
\hline
\end{tabular}


Table 2: Depicting association between different characteristics and clinical features of patients.

\begin{tabular}{|c|c|c|c|c|c|}
\hline \multicolumn{2}{|l|}{ Characters of pts } & \multirow{2}{*}{$\begin{array}{l}\text { Fever } \\
n=(\%) \\
13(36.1)\end{array}$} & $\begin{array}{l}\text { earache } \\
n=(\%)\end{array}$ & $\begin{array}{l}\text { Orchits } \\
n=(\%)\end{array}$ & $\begin{array}{l}\text { Bl parotitis } \\
n=(\%)\end{array}$ \\
\hline \multirow{2}{*}{ gender } & Male (36) & & $24(66.7)$ & $1(28)$ & $36(100)$ \\
\hline & Female (19) & $10(52.6)$ & 11(57.9) & $0(0.0)$ & 19(100) \\
\hline Fishers Exact test & 0.26 & 0.56 & 1.0 & -- & \\
\hline \multirow[t]{2}{*}{ Age group(yrs) } & $4-8(n=48)$ & 19(39.6) & $34(70.8)$ & $0(0.0)$ & $48(100)$ \\
\hline & $9-12(n=7)$ & $4(57.1)$ & $1(14.3)$ & $1(14.3)$ & 7(100) \\
\hline Fishers Exact test & 0.43 & $0.007 *$ & 1.00 & -- & \\
\hline \multirow[t]{4}{*}{ Habitat } & Rural $(n=49)$ & & & & \\
\hline & $23(46.9)$ & $30(61.2)$ & $1(2.0)$ & 49(100) & \\
\hline & $\operatorname{Urban}(n=6)$ & & & & \\
\hline & $0(0.0)$ & $5(83.3)$ & $0(0.0)$ & $6(100)$ & \\
\hline Fishers Exact test & & $0.035 *$ & 0.39 & 1.00 & -- \\
\hline
\end{tabular}

From the table it is evident that the earache is significantly higher in the lower age group i.e 4-8yrs) $(p<0.05$. It is also seen that the most of the cases which are from rural areas suffer from fever $(P<0.05)$ which is significant. The data was subjected to biostatistical analysis by Fisher exact test using SPSS version 12 .

\section{Results and Observations :}

A total of 55 patients both males and females were incorporated in the study from 2007-2011. (Table 1) All the pts presented in summer in the month of August. In the year 2010 no case was seen which can be ascribed to unfavorable circumstances/or war like situation, due to which these patients could not visit the hospital. The history was remarkable. All these patients ( $N=55$ had h/o of contact with raw/or semi-ripened walnuts in the form of fondling and or eating. None of the children had received any dose of mumps/MMR vaccination. Almost all the children were school going and presented in groups. Out of 55 patients, males were 36 and females were 19.The 48 children were in the age group 4-8 yrs and remaining 7 were of 9-12 yrs age. As per the habitat 49 patients were from rural area and 6 were from urban area. All the patients $(100 \%)$ were having bilateral parotid enlargement, the hallmark of mumps. (Table 2) Fever was present in 13 (36.1\%) boys and in 10 (52.6\%) girls. The fever was usually mild and self-limiting or $57.1 \%$ of children having fever were in age -group of 9-12 years. Among the children in whom fever was present, rural group 23 (100\%) as compared to urban $0(0 \%)$ were febrile which is significant $p=<0.05$. Earache was present in $24(66.7 \%)$ males and in 11 (57.9\%) females .However it was more frequent in younger children $(70.8 \%)$ compared to older (14.3\%) which was statistically significant. Earache was present in both rural and urban group. Orchitis was present only in single male 11 year rural child.

\section{Discussion :}

Mumps outbreaks that do occur in India and in many other countries are comparable to this study in respect to epidemiology besides clinical features. All the patients who were incorporated in the study had denovo mumps as they had never received any sort of vaccination (mumps vaccine/MMR) for mumps. In our study all these patients presented yearly in the hot season of summer, the month of August and were 4-12 yrs school going children with male preponderance. The outbreak reported from in Kerala in 2002 had almost similar epidemiological trend as for as age, gender and vaccination status is concerned but epidemics occurred cylically after every 5-10 yrs in the cooler months of year from January -to ending March. ${ }^{6}$ Ghatage et al reported that miniepidemics occurred in Maharashtra, South India in the months of December and January and in children with prior history of vaccination which is quite different from our study but other features were similar to our study. In yet an other study at Pune, India 1999 some of findings were similar to our study. ${ }^{8}$ In UK $79 \%(2 / 3)$ of patients with mumps in 2004 epidemic were unvaccinated public. ${ }^{9}$ The outbreaks in Canada were not different from our study in respect to season as they 
used to occur from May-september where as in US they used to occur in months of winter and spring. Moreover in US/Canada outbreaks used to occur cyclically after every 25 yrs. This in contrast to our study, where we have been watching mini-outbreaks yearly. In European and US / Canadian studies on adolescent children from age group of 18-24 yrs. were involved ${ }^{10}$ where as no child/boy of this age presented to our med unit. In our study besides not being vaccinated against mumps there was a unique history of contact with walnuts, raw/ semiripened in the form of either handling and or eating in all patients which was noteworthy. Such a thing has never been noticed and or reported previously. The walnuts could act as fomites and or reservoir of the mumps virus. To corroborate such an association needs further clinical trials and laboratory studies. Here it is worthwhile to mention that rural population was involved more due to the fact that walnut trees which are in abundance in this area of South Kashmir. In our study males were mainly infected, which is consistent with other studies. ${ }^{8,9,10,11}$.In our study all patients were having bilateral parotitis (100\%) where as in a study at Maharahtra, $50 \%$ were having bilateral and 50\% unilateral parotitis. In our study bilateral parotitis was associated with mild to moderate fever in $88.7 \%$ and was frequent in rural patients. The fever was self limiting or

\section{References:}

1. CDC - Mumps: Outbreaks, www.cdc.gov/mumps/outbreaks.html 6 Oct 2010 - In 2006, the United States experienced a multi-state outbreak involving 6584 reported cases of mumps.

2. Rima BK and Christie AB (1995) "Mumps: epidemic parotitis". In Weatherall D, Leddingham JGG and Warrell DA (eds) The Oxford Textbook of Medicine, pp. 372-375. Oxford: Oxford University Press.

3. Anne Gershon. "Mumps" in :Fauci , Braunwald, Kasper, Hauser, Longo, Jameson, Loscalzo.(17 the edition" of Harrisons Principals of internal medicine. Volume 1,2008 pp 1220-1221. Mac Graw Hill companies.

4. Mumps and rubella elimination from Finland.JAMA 2000; 284: 2643-2647.

5. D Schmid ${ }^{1}, \mathrm{H}$ Holzmann ${ }^{2}, \mathrm{C}$ Alfery ${ }^{1}, \mathrm{H}$ Wallenko ${ }^{3}, \mathrm{~T}$ H Popow-Kraupp ${ }^{2}, \mathrm{~F}$ Allerberger. OUTBREAK IN YOUNG ADULTS FOLLOWING A FESTIVAL IN AUSTRIA, 2006 Eurosurveillance, Volume 13, Issue 7, 14 February 2008

6. John TH. An outbreak of mumps in Thiruvananthapuram district Indian Pediatr 2004; 41:298-300.

7. S.T. Ghatage,Girish M. Kakade. An Outbreak of Mumps Meningoencephalitis in Sangli District.INDIAN PEDIATRICS 2007; 44:235

8. S. K. Raut1,P. S. Kulkarni1, *, M. A. Phadke2, S. S. Jadhav1,S. P. Dhorje1. Persistence of Antibodies Induced by Measles-Mumps-Rubella Vaccine in Children in India? Clin Vaccine Immunol October 2007 vol. 14 no. $101370-1371$

9. Ravindra K Gupta, Jennifer Best, Eithne MacMahon, Mumps and the UK epidemic 2005.BMJ 2005; 330 doi: 10.1136/bmj.330.7500.132 (Published 12 May 2005)

10. H Bernard, N G Schwarz, A Melnic, V Bucov, N Caterinciuc, R G Pebody, usually subsiding with antipyretics in couple of days. The parotid swelling and earache would settle in2-5 days time which is in concordance to other studies. ${ }^{2,12,13,16}$. In a study done in South India, epidemics were associated with significant loss of school going or working days ${ }^{7}$ which is also an important noteworthy finding of our study. Orchitis was present in a single but older patient, which is compatible with all other studies. ${ }^{3,4,17,18}$

\section{Conclusions \& Recommendations :}

The outbreaks in this part of world have special trend with respect to age group, seasons and frequency. There being a unique history of walnut exposure in unvaccinated people. Further observational studies are needed to see any real link between semi-ripened walnuts and Mumps. Fortunately epidemics were having self-limiting course, but still lead to loss of working and/or school days. Therefore regular vaccination should be considered as an important step in minimizing clinical outbreak and working for possible eradication of the disease. For this reason it is vehemently pleaded to include mumps or MMR vaccine in national immunization schedule. Since mumps is highly contagious, it is recommended to create awareness in general population about the disease, so that infected children are confined to their respective homes and kept away from schools.

M Mulders, C Aidyralieva, S Hahné MUMPS OUTBREAK ONGOING SINCE OCTOBER 2007 IN THE REPUBLIC OF MOLDOVA Eurosurveillance, Volume 13, Issue 13, 27 March 2008

11. Heikki Peltola1, Prasad S. Kulkarni2, Subhash V. Kapre2, Mikko Paunio3, Suresh S. Jadhav2, and Rajeev M. Dhere .Mumps Outbreaks in Canada and the United States: Time for New Thinking on Mumps Vaccines.Clin Infect Dis. (2007) 45 (4): 459-466.

12. Kanra G, Isik P, Kara A, Cengiz AB, Seçmeer G, Ceyhan M.Complementary findings in clinical and epidemiologic features of mumps and mumps meningoencephalitis in children without mumps vaccination. Pediatr Int. $2004 \mathrm{Dec} ; 46(6)$ :663-8.

13. Gut JP, Lablache C, Behr S, Kirn A. Symptomatic mumps virus reinfections. J Med Virol 1995; 45:17-23. (PMID 7714488)

14. Roberto Casella, Bernhard Leibundgut, Kurt LehmannThomas C. Gasser. MUMPS ORCHITIS: REPORT OF A MINI-EPIDEMIC, The Journal of Urology Volume 158, Issue 6, Pages 2158-2161, December 1997

15. Sangita Yadav, Richa Thukral \& Anita Chakarvarti* Comparative evaluation of measles, mumps \& rubella vaccine at $9 \& 15$ months of age. Indian J Med Res 118, November 2003, pp 183-186

16. Gustavo H. Dayan, M.D., M. Patricia Quinlisk, M.D., M.P.H., Amy A. Parker, M.S.N., M.P.H., Albert E. Barskey, M.P.H. N Engl J Med 2008; 358:1580-1589April 10, 2008

17. J Mossong , Ch Bonert ${ }^{2}$, P Weicherding ${ }^{3}$, M Opp $^{1}$, P Reichert ${ }^{1}$, J Even ${ }^{1}$, F Schneider MUMPS OUTBREAK AMONG THE MILITARY IN LUXEMBOURG IN 2008: EPIDEMIOLOGY AND EVALUATION OF CONTROL MEASURES. Eurosurveillance, Volume 14, Issue 7, 19 February 2009 